China Perspectives

54 | July- August 2004

Varia

\title{
A Bilateral Trade Agreement Between Hong Kong and China: CEPA
}

Bruno Cabrillac

\section{(2) OpenEdition \\ Journals}

Electronic version

URL: http://journals.openedition.org/chinaperspectives/3002

DOI: $10.4000 /$ chinaperspectives.3002

ISSN: 1996-4617

Publisher

Centre d'étude français sur la Chine contemporaine

\section{Printed version}

Date of publication: 1 July 2004

ISSN: 2070-3449

Electronic reference

Bruno Cabrillac, « A Bilateral Trade Agreement Between Hong Kong and China: CEPA », China Perspectives [Online], 54 | July-August 2004, Online since 29 December 2008, connection on 28 October 2019. URL : http://journals.openedition.org/chinaperspectives/3002 ; DOI : 10.4000/ chinaperspectives.3002

This text was automatically generated on 28 October 2019

(c) All rights reserved 


\title{
A Bilateral Trade Agreement Between Hong Kong and China: CEPA
}

\author{
Bruno Cabrillac
}

\section{EDITOR'S NOTE}

Translated from the French original by Michael Black

1 On June 29th 2003 the Special Administrative Region (SAR) of Hong Kong and mainland China signed a bilateral trade agreement, known by its English acronym as CEPA (Closer Economic Partnership Arrangement) ${ }^{1}$. This agreement is made up of three sections: tariff reductions on 273 categories of goods that Hong Kong exports to the People's Republic of China (PRC); a preferential opening of the Chinese market to Hong Kong service providers in 17 sectors (increased to 18 in September 2003); and a series of measures aimed at facilitating bilateral exchanges of goods, capital and people. On September 29th 2003, Hong Kong and the PRC signed six annexes to the main agreement. The aim of these annexes was to clarify and complete the original provisions of the CEPA. Annexes 1 to 3 deal with trade in goods and define, in particular, related rules, the origin of the goods and the procedures for registration and verification of certificates of origin. Annexes 4 and 5 deal with the second section of the agreement, with the addition of the telecommunications sector, and the definition of the term "Hong Kong service provider". Annex 6 defines six fields for special cooperation between Hong Kong and China.

2 With the exception of a certain number of these measures (opening up in the telecommunications sector, the provision of individual visas for tourists from certain regions of mainland China visiting Hong Kong...), which were implemented in the autumn of 2003, the agreement came into effect on January 1st 2004. Both parties have committed themselves to continue negotiations to extend this agreement at a later 
stage. The CEPA conforms to Article 24 of the GATT (General Agreement on Tariffs and Trade) on bilateral agreements and is compatible with the rules of the World Trade Organisation (WTO), which was an essential condition of its application, since both parties are separate members of the WTO. This is the first bilateral agreement to be signed by Hong Kong and the first to be signed by mainland China with a member of the WTO.

3 This agreement is the result of an initiative on the part of business circles and more particularly by the Hong Kong General Chamber of Commerce (HKGCC), in response to anxieties about the future of the SAR as a "gateway" between China and the rest of the world, which were fuelled by the economic slowdown in 2001. Despite its reservations, the government of Hong Kong backed the initiative and obtained, in December 2001, an agreement in principle from the central government. It took eighteen months to conclude the CEPA.

4 The unilateral concessions accepted by mainland China have limited practical range. The tariff reductions concern only a very small part of a bilateral trade which has shrunk rapidly in the last few years. The preferential measures allowed Hong Kong service providers certain advantages which, in most cases, are limited in concrete terms as well as in time, as they come ahead of the measures inscribed in the calendar for the liberalisation called for in China's protocol for entry to the WTO. Such advantage is even in doubt in some sectors, due to the acceleration of China's opening up. Of greater significance is the symbolic reach of this agreement. It firstly emphasised the commitment of the Chinese authorities to maintaining Hong Kong's prosperity, although the reinforcing of this commitment may appear as compensation for a highly conservative approach to political reform. Above all, it allowed Hong Kong to benefit in terms of image by reminding all concerned that, on the one hand, the Hong Kong economy would be one of the principal beneficiaries of China's accession to the WTO, and that, on the other, the principle of "one country, two systems" produces significant benefits for the Special Administrative Region.

China agrees to unilateral tariff reduction

5 Since January 1st 2004, 273 categories of products (according to the nomenclature of the Chinese customs) of Hong Kong origin are no longer subject to import duties to mainland China. Included are many of products related to watches, jewellery, textiles and clothing, chemicals, pharmaceuticals, cosmetics, and the electrical and electronics industries. PRC import duties remain high on some of these products: from $27 \%$ to $35 \%$ for jewellery, from $18 \%$ to $22 \%$ for cosmetics, from $14 \%$ to $23 \%$ for watches, and from $5 \%$ to $30 \%$ for electrical and electronic products. The agreement is to be extended from January 1st 2005 to further categories of products as proposed by Hong Kong exporters and approved by the Hong Kong and Chinese authorities. As of January 1st 2006, all exports of products of Hong Kong origin will be exempted from import duties.

The definition of the "rules of origin" of products is spelled out in Annex 2. About 67\% of the 273 products covered by the agreement (including jewellery, textiles, clothing, cosmetics, paper, and plastics) are covered by the criteria of origin currently in force in Hong Kong, in conformity with Article VII of the GATT which requires "substantial transformation", defined case by case. In $17 \%$ of categories, among them chemical and metal products and certain electronic products, this "substantial transformation" must be significant enough to lead to a change in tariff heading, according to the international four-digit nomenclature. The agreement thus uses the provision, which is 
fairly widespread in matters of product origin, of Change in Tariff Heading. Finally, for the remaining $16 \%$ of categories (among them watch and optical components) the production or transformation costs in Hong Kong (including product development costs) must represent at least 30\% of the FOB (Free On Board) export price. While Hong Kong had to make concessions to the Chinese on this percentage (their objective had been to set this at $25 \%$ ), they were nevertheless successful in having development costs included in the calculation.

7 Annex 1 and Annex 3 respectively stipulate the conditions for the drawing up by both parties of complementary lists of products eligible for the lifting of tariffs on entry to mainland China, and the formalities for obtaining certificates of origin.

8 Hong Kong being a duty-free region, the concessions agreed to by China are of a unilateral character, although they are formally linked, in the agreement, to Hong Kong's commitment not to impose any restrictions on imports coming from the PRC. Moreover, both parties have committed themselves not to take any mutual protectionary measures nor engage in anti-dumping procedures, this last agreement formalising practice at present.

A measure with limited effect

9 According to the Hong Kong Government, $90 \%$ of exports of Hong Kong origin to China will be exempt from tariffs once the agreement comes into force. Hong Kong's domestic exports to the mainland reached HK $\$ 36.7$ billion (US $\$ 4.7$ billion) in 2003; they represent $30 \%$ of total Hong Kong product exports, but only $2.1 \%$ of Hong Kong's total exports which include, in particular, Chinese products in transit through Hong Kong. The flow has slowed significantly since 1997, due to delocalisation, now almost complete, of Hong Kong's manufacturing industry. 
Exports of products of Hong Kong origin to Mainland China (billions of HK\$)

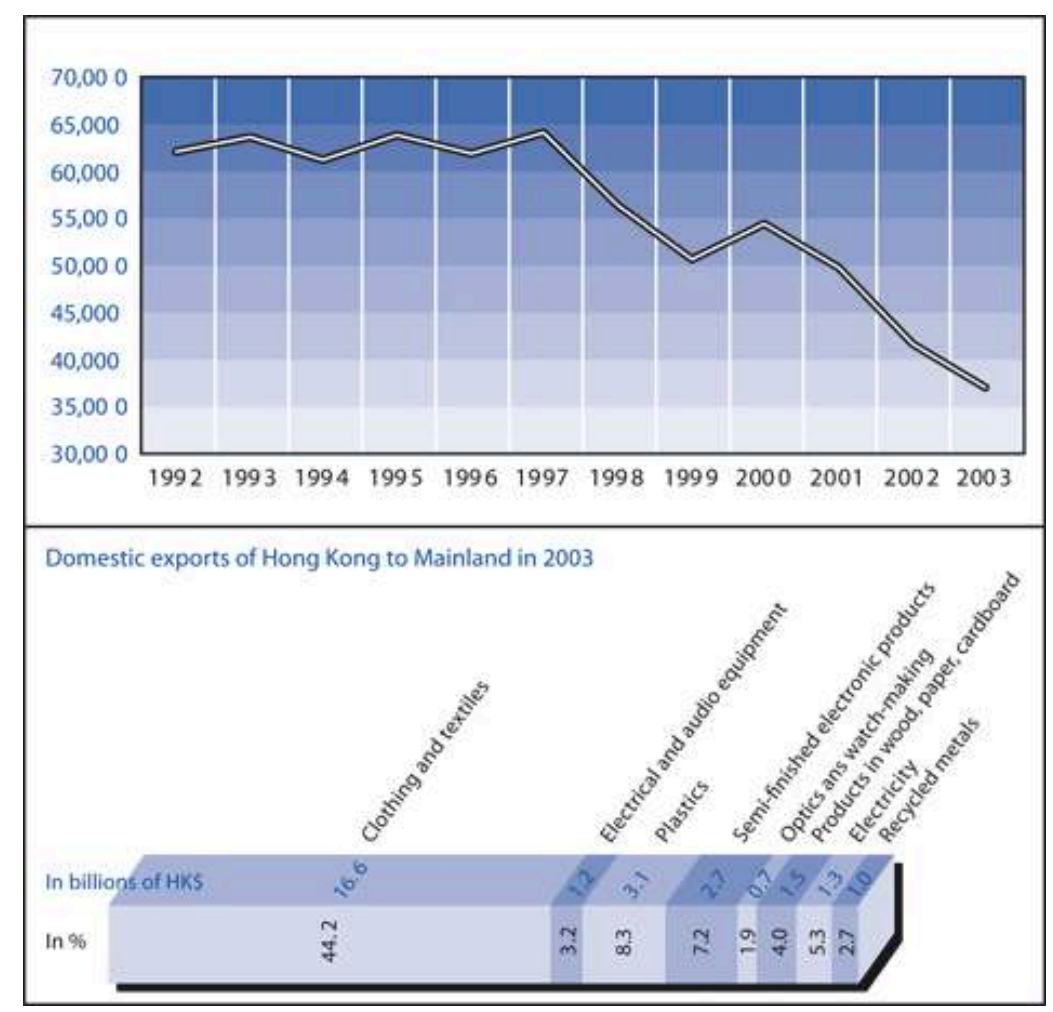

Source: Census and Statistic Department, Hong Kong.

10 Over two-thirds (70\%) of these trade flows are, moreover, linked to outsourcing operations or exchanges within companies which are, to a large extent, already tarifffree. Thus the overall "static" benefit (i.e. based on exports in 2003) from the lowering of tariffs is estimated, apparently generously, by the Hong Kong Government at HK\$750 million (US $\$ 100$ million), or less than $2 \%$ of total Hong Kong domestic exports to the PRC. On the scale of Hong Kong's economy, this benefit is not significant.

11 Over the first four months of the agreement, in the framework of the CEPA, 869 certificates of origin were requested and 813 approved, mostly in textiles and clothing (310 approved) and pharmaceutical products (209 approved). During the first quarter of 2004, the fall in exports of products of Hong Kong origin to China continued, albeit more slowly than in $2003(-8.4 \%$ as against $-11.9 \%)$, without it being possible to attribute this change to the CEPA. The value of products made tariff-free thanks to the CEPA amounted to less than HK\$400 million (US\$50 million) between January 1 st and May 21st 2004.

12 Can one expect, from this lowering of tariffs, the emergence of new manufacturing activities in the SAR? Taking into account the differences in costs between mainland China and Hong Kong, in particular real estate and labour costs, the tariff benefits seem, on the face of it, insufficient to encourage manufacturers to locate some of their production capacities in Hong Kong. The Hong Kong authorities and business circles have nonetheless identified certain products whose manufacture in Hong Kong may be potentially profitable in the light of the clauses in the CEPA: either they are subject to high tariffs on entry to China (like jewellery, ice cream, and certain parts for consumer electronics) or they have a high immaterial content (such as brand, design or technological innovation) which corresponds to Hong Kong's comparative advantages 
(in perfume, eyewear, clothing and tableware). Intellectual property rights protection, strong in Hong Kong, weak or non-existent in China, constitutes a factor likely to compensate the cost differential in the production of this last category of goods.

More than forty requests have been made to extend the scope of the CEPA to cover other products which, in most cases, are not manufactured in Hong Kong. But the procedure for extending the agreement is long and complex, and the abolition of tariffs cannot take effect until January 1st 2005. In any case, this would only provide a year's advance on the total abolition of tariffs on all domestic exports of Hong Kong to mainland China on January 1st 2006.

Six months after the application of the agreement, projects are still slow to materialise, although some interest has been expressed. Neither business circles nor the authorities harboured any illusions in that regard. Thus the Hong Kong Trade Development Council, the organisation which promotes Hong Kong's foreign trade and a keen supporter of the CEPA, indicated in November 2003: "the creation of manufacturing activities thanks to the CEPA is likely to be limited and the effects in terms of employment creation or of trade flows is likely to be moderate". The HKGCC points out the existence of projects in textiles (Ralph Lauren), biotechnology (CK Life Sciences), chemicals, Chinese medicine products, perfumes and even the steel industry. The creation, as called for by business circles, of a special trans-border zone where companies could, on Hong Kong territory, employ mainland Chinese workers, would no doubt make it possible to increase the benefits of the CEPA in this domain.

A preferential opening in servicesMeasures of varying importance

The CEPA covers, by means of a restrictive list of 18 subsectors, most of the services sector, in particular financial services (banking, insurance, security transactions, asset management), various services to companies (legal advice, auditing, accounting), transport, logistics (including warehousing and services for goods in transit), building and public works, retailing, health, tourism, audiovisual, advertising, the organisation of fairs and exhibitions, and telecommunications. The range of the agreement is thus very wide, although in some sectors the concessions made are very limited. It is noticeable that the education sector is not included, despite Hong Kong's ambitions in that area.

16 The preferential opening measures, highly variable according to sector, generally include a shortening of the calendar for liberalisation provided for in the framework of China's entry protocol to the WTO and/or additional liberalisation measures and/or a relaxing of the access criteria applied to foreign companies. There again, it is a largely unilateral commitment, although Hong Kong is committed to not taking any new discriminatory measures against the PRC, for access to the 18 subsectors covered by the agreement. This second clause may provide mainland China with some benefits: the growth of Hong Kong direct investment, and the acquisition of know-how ahead of the opening of the services sector to foreign competition.

17 Over and above the diversity of sectors, Hong Kong service providers will benefit from three main advantages:

- They will benefit before foreign companies from the liberalisation measures provided for in the protocol for entry to the WTO. This advantage is time limited (four years at most but generally less than two years), and is based on the supposition that there is an advantage to the first mover, which remains to be demonstrated. 
- They will benefit from opening measures which go beyond the framework of the WTO entry protocol. In this case, as above, the main advantage conceded to Hong Kong service providers is the possibility of creating a wholly-owned subsidiary or of holding a majority stake or a controlling minority in joint ventures. As relations with the Chinese partner, who is often imposed by the authorities, are often difficult and generate significant direct costs (remuneration higher than the real contribution made), or indirect costs (differences in strategy), this advantage is substantial.

- Lastly, they will be subject to lower quantitative thresholds of access to the Chinese market than those applied to foreign companies. The most characteristic example is the reduction from US $\$ 20$ million to US\$ 6 million of the minimum assets required for a foreign bank to open a branch in mainland China.

Table 2 summarises the assessment by Hong Kong business circles of this second section, just after it was signed. One must point out that this assessment has been made partly obsolete by the evolution of Chinese legislation. The liberalisation measures introduced in early 2004, in the retail and import/export sector, have wiped out the main advantages contained in the CEPA. In contrast with the tariff clause, the liberalisation of services has been hailed in business circles as significant or even substantial progress. "The impact of the CEPA on the services sector should be much greater than that on the manufacturing sector", was the judgement of the Hong Kong Trade Development Council; "the CEPA is an exceptional opportunity for the Hong Kong services industry" wrote the HKGCC.

Assessment by the Hong Kong General Chamber of Commerce of the effects of the services clause of the CEPA

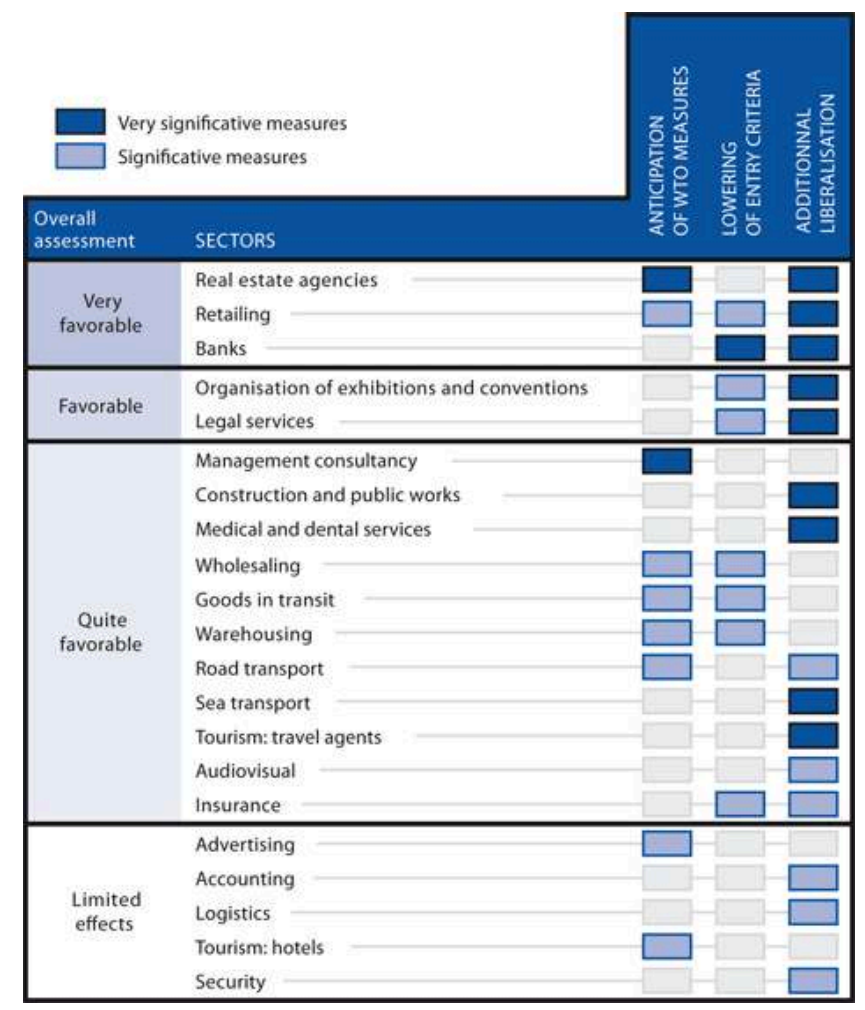

Source: Hong Kong General Chamber of Commerce.

A very open definition of Hong Kong companies 

clause of the agreement, all the more so as the GATT and WTO texts give little detail on this subject. Both parties finally agreed on a pragmatic and open definition, based on participation in the economic activity of the SAR rather than on the nationality of the capital holders. Annex 5 of the CEPA contains a definition of a Hong Kong company, with variable parameters depending on the services industry concerned, which is based on three criteria:

- The company must have been registered in Hong Kong in accordance with Hong Kong company law, the subsidiaries of foreign companies being excluded (in this respect, one should point out the case of Standard Chartered, one of the three commercial banks which issues the Hong Kong dollar, but which, being established in Hong Kong as a branch, has not been eligible for the benefits of the CEPA).

- It must have substantial activity, the evidence for which is based on an analysis of four distinct criteria: the nature and volume of business carried out in Hong Kong, liability to Hong Kong profits tax, at least three years of existence and business activity (five years in the construction and engineering sectors, no such condition being imposed on real estate agencies), and the existence of wholly owned or leased offices, mere "post boxes" being excluded from the benefits of the agreement.

- The company must employ at least $50 \%$ of its personnel in Hong Kong.

The description "Hong Kong service provider", which bestows the right to the exceptional advantages given in the field of services, is extended in Annex 5 to physical persons, provided they have the status of permanent resident in Hong Kong. Annex 5 stipulates the procedure for obtaining the description of "Hong Kong service provider".

It is none the less noticeable that benefits from the opening of the legal profession and of insurance actuaries are reserved for residents of Hong Kong who are Chinese citizens (a necessary precondition for Hong Kong citizenship), thereby excluding residents, even permanent, of foreign origin, who are very numerous in these professions. Similarly, permission to open a retail business in Guangdong without a Chinese partner is reserved for Chinese citizens. Apart from these exceptions, the definition agreed for "Hong Kong company" is very open, and does not discriminate against companies with foreign capital, or service providers of foreign nationality. This open definition, which in accordance with Hong Kong's vocation as an international services market, is one of the PRC's major concessions in this agreement.

The direct consequences are likely to be disappointing

The Hong Kong authorities, professional bodies and chambers of commerce have made major communication and promotion efforts about the second clause of the CEPA, which they consider to be promising, aimed at the local business community and abroad. The number of requests made to the Hong Kong authorities (298 at the end of April 2004, of which 242 have been approved) is significant. Most of the requests come from three sectors: logistics (157), retailing (65) and advertising (23). It is noteworthy that the recent measures for the liberalisation of retailing and import/export activities may wipe out the advantages that the CEPA may offer in these sectors. Among other sectors showing interest are telecommunications (in services with high added value), engineering, the organisation of fairs and exhibitions, and banking. In the banking sector in particular, two of the eight Hong Kong banks which can potentially open branches in China through the CEPA, have done so. 

because of the difficulties of application of the CEPA in the mainland. The Chinese authorities have stated that they have made most of the legislative effort necessary: 26 of the 29 texts which had to be amended for the CEPA to come into effect have been amended, and the legislative and regulatory work should have been finished before mid-2004. The enforcement of the agreement remains problematical, however: the procedure is complex and opaque, and decisions are subject to the bureaucracy of central government, and then to the arbitrary nature of local authorities. Pressure from the Hong Kong authorities and business circles has made it possible to simplify procedures (for example in Shanghai and in Guangdong, where a single office has been set up to deal with CEPA authorisations), but the number of administrations involved in certain sectors is very high. Lastly, the CEPA is no exception to the rule that in China a number of irregular obstacles tend to substitute for legal obstacles which have been abolished or relaxed. In this context, many Hong Kong service providers stick with the solutions they had in many cases already established, in order to adapt to Chinese regulations or to get around them.

The impact must also be assessed in terms of the attracting of new investment to Hong Kong. The HKGCC and business circles point to some interest as indicated by several announcements and plans for mergers and acquisitions linked to this clause of the CEPA (for example the acquisition by the Hong Kong bus company KMB of a Chinese company, and the plan for the Standard Chartered Bank to buy a Hong Kong bank in order to benefit from the CEPA).

Subsidiary and complementary measures with major effects

Overshadowed by the main measures, some secondary provisions of the CEPA have already had major effects on the Hong Kong economy. For example the possibility, which is an exception to the existing legislation, for tourists from certain cities and regions of mainland China to travel individually to Hong Kong has boosted the growth of Chinese tourism in the SAR. Almost three million Chinese tourists visited Hong Kong in the first quarter of 2004 (an increase of $40 \%$ compared with 2003), of whom nearly $40 \%$ had an individual visa. In this domain, the Hong Kong authorities are hoping to hear very soon that the SAR's travel agents will be allowed to offer foreign packages to groups of Chinese tourists, under the same conditions as Chinese travel agents.

Moreover, the authorisation given to Hong Kong traders to open shops under their own names and without any access conditions, in Guangdong province, has already, according to the HKGCC, led to the opening of 400 outlets.

Numerous complementary measures to facilitate the movement of people and capital between China and Hong Kong have been taken over the last few months and are part of the spirit, if not the text, of the agreement. Among the most important are to be noted the relaxing of exchange controls (the raising of currency exit ceilings for Chinese tourists going to Hong Kong, the possibility for Hong Kong banks to offer services in renminbi) and the reciprocal recognition of qualifications and/or establishment of professional examinations (for architects, site managers, building and structure engineers, insurance agents, intellectual property consultants...). This preferential treatment makes it possible for Hong Kong to position itself no longer as merely the market for China's external financing but as the market for the management of Chinese savings invested abroad. The reciprocal recognition of qualifications is a necessary condition for the effectiveness of the second section of the

China Perspectives, 54 | July- August 2004 
CEPA. Moreover, the Hong Kong authorities are concentrating their efforts in these two fields, by negotiating an extension of reciprocal recognition in particular in the medical, legal and accounting professions, and a relaxation of exchange controls for the investment of Chinese portfolios invested or managed in Hong Kong.

Powerful symbolic and political effects

The CEPA is highly significant politically. Signed at the end of June 2003 on the occasion of the official visit by the new Chinese Prime Minister, Wen Jiabao, to the SAR, the agreement shows that the maintenance of Hong Kong's prosperity remains the essential objective of the PRC's policy towards the SAR, in particular because the Chinese authorities see it as the main factor in the maintaining of political stability in Hong Kong, as well as in the success of the "one country, two systems" principle. The CEPA thus constitutes the most visible sign of the desire of the Chinese authorities to make Hong Kong benefit from China's growth, by accentuating economic interpenetration, without calling into question the total autonomy of Hong Kong's economic territory, which has also been symbolically reinforced by the conclusion of a bilateral trade agreement.

In terms of image, the benefits to Hong Kong are considerable. The manifest convergence of interests demonstrated by the CEPA, between Hong Kong and the central authorities, makes the refrain about the decline in Hong Kong's role as the market for services to and from China less accurate. The Hong Kong authorities now have at their disposal regulatory measures to provide arguments for the importance of this role, even though non-regulatory comparative advantages (the guanxi, linguistic and professional capabilities, experience of both Chinese and foreign markets) remain decisive.

Moreover, the CEPA is the first bilateral commercial agreement to have been signed by Hong Kong. Another agreement is under negotiation with New Zealand. While the Hong Kong authorities do not question the priority given to multilateral negotiations, they make no secret of their desire to participate, as does Singapore, in the proliferation of bilateral and regional agreements in order to enhance the SAR's image as a regional trading market.

31 Beyond its direct consequences, the CEPA recalls and highlights some major features of economic relations between Hong Kong and China which are often forgotten or overlooked. The two economies are increasingly interdependent and, particularly, the Hong Kong economy's dependence on the PRC has grown considerably. The two economies are still not so deeply integrated: the movement of goods, people and capital is regulated and thus limited. Greater integration is possible, although it will quickly reach its limits, on the one hand if the principle of "one country, two systems" is not to be called into question, and on the other hand because of the extent of the differences in levels of development and per capita income. Interpreted pragmatically, the ambiguities of the slogan "one country, two systems" remain fertile in economic terms. Economic territory independent from China, but under Chinese sovereignty, Hong Kong has a legal and judicial system totally independent of and different from China's. And Hong Kong's geopolitical situation remains one of, if not its principal, comparative advantage. 


\section{APPENDIXES}

The principal measures in the services sector ${ }^{2}$

\section{Strategy consultancy}

With the exception of certain types of strategy consultancy, Hong Kong companies have the right to set up, four years ahead of the WTO calendar, wholly-owned companies in mainland China. The minimum capital required is likely to be the same as for Chinese companies, i.e. 100,000 yuan (as against the present amount of between US $\$ 100,000$ and US $\$ 500,000$ for foreign companies).

The agreement does not define the legal form in which Hong Kong companies will be able to establish wholly-owned companies in mainland China. The legal form authorised could have numerous implications for Hong Kong investors, in particular concerning the possibility of repatriating profits.

Moreover, it is unlikely that CEPA will apply to consultancy companies in the education and training sectors (in which Hong Kong has major expertise) in as much as these sectors are highly controlled by the Chinese authorities.

\section{Accounting}

Hong Kong accountants who have already obtained mainland China's diploma in accountancy and have exercised their profession on the mainland, are treated on an equal footing with mainland Chinese accountants where the annual number of working hours in the PRC is concerned.

The validity of the temporary licence for accountancy, given to Hong Kong auditors to carry out assignments in mainland China, has been extended from 6 months to 1 year. It is interesting to note that the requirement to obtain a licence is a restriction peculiar to China which does not correspond to the norms in force in OECD countries (a foreign accountancy firm can, for example, freely carry out an accountancy assignment in Hong Kong, without government authorisation). In 2003, Hong Kong accounting firms had opened 18 representative offices and seven joint ventures in China.

\section{Banking}

The agreement makes clear the Chinese government's desire to provide Hong Kong, up to 2007, with a privileged means of access to the Chinese banking market. CEPA facilitates access by Hong Kong banks to the Chinese market and will give them a comparative advantage over foreign banks until the end of the calendar of application of WTO commitments (cf. annex 3). It does not, however, lift the totality of restrictions which apply in the banking sector, in particular on operations in renminbi.

For the Hong Kong banks CEPA:

- lowers the threshold of the amount of assets required for a foreign bank wishing to establish itself in China, from US $\$ 20$ billion to US $\$ 6$ billion; this measure should allow eight of the Territory's banks to establish themselves in mainland China.

- allows them to offer services in yuan and in currency two years after opening a branch, as against the three presently required for a foreign bank; whereas mainland China demands that foreign banks make a profit in each of their branches in order to obtain a licence in local currency, CEPA provides that a profit from the overall group of establishments will suffice for a Hong Kong bank to be able to offer its services in renminbi. 
- removes the obligation to set up a representative office before the establishment of a bank in partnership.

- Moreover, CEPA affirms the support of the Chinese authorities for mainland Chinese banks who wish to move their foreign exchange and cash transaction centres to Hong Kong (where currency is freely convertible and there are no controls over capital), or develop a presence in Hong Kong via acquisitions.

\section{Financial markets}

CEPA authorises the operator of the Hong Kong Stock Exchange, Hong Kong Exchanges and Clearing, to open a representative office in Peking.

Hong Kong stock market professionals can request to exercise their profession in mainland China according the procedures in force. CEPA does not therefore bring any substantial modification to the sector, which is gradually opening to foreign participants, in particular with the application of new regulations which allow a few selected foreign investors, Qualified Foreign Institutional Investors (QFII), freer access to Chinese capital markets; the establishment of QFII being totally disconnected from CEPA.

\section{Insurance}

CEPA makes the following provisions:

- Hong Kong residents of Chinese nationality can exercise their profession in mainland China without any prior agreement after having obtained the mainland Chinese professional actuary diploma.

- Hong Kong insurance companies can access the mainland Chinese market through a strategic merger with a local concern, as long as they abide by the conditions spelt out in China's accession agreement to the WTO (no Hong Kong company is concerned).

- The ceiling on capital investment in a mainland Chinese company is raised from $10 \%$ to $15 \%$ for Hong Kong insurance companies.

\section{Health}

The majority of people working in hospitals and clinics which are joint enterprises between Hong Kong and the PRC can be permanent residents of the SAR, as an exception to the rule applied to foreigners.

The maximum length of permits to exercise in the PRC will be extended to three years for doctors licensed to exercise in Hong Kong, as against one year for other foreign doctors.

CEPA opens to permanent residents of Hong Kong who are graduates of Hong Kong University or of the Chinese University of Hong Kong, examinations for access to the medical professions in the PRC.

\section{Advertising, tourism, public relations}

Hong Kong companies are allowed to create wholly-owned subsidiaries.

Audiovisual

- Hong Kong audiovisual product distribution companies (including cinema products) can form joint enterprises with one or several mainland Chinese companies and hold up to $70 \%$ of the capital.

- In the framework of accession to the WTO, China has committed itself to opening its market to 20 foreign films per year. Films in Chinese produced by Hong Kong companies will be distributed outside this quota. 
- Films co-produced by Hong Kong and Chinese companies will be considered to be Chinese films. The restrictions applied to these co-productions (percentage of Chinese personnel, links with China) have been relaxed.

- Construction renovation and operation of cinemas in the framework of a joint venture: Hong Kong companies are allowed to make a majority stake of up to $75 \%$ in joint ventures in this sector (only a minority stake was allowed in the WTO agreement).

\section{Legal services}

The minimum residence requirement for all Hong Kong representatives in the representative offices of firms of lawyers in the People's Republic is reduced from six to two months per year. Hong Kong practitioners are licensed to work for PRC firms. The fifteen or so Hong Kong lawyers who have acquired a People's Republic professional diploma are allowed to exercise in all non-contentious legal matters.

Hong Kong permanent residents with Chinese citizenship are allowed to sit the professional law examinations in the PRC and will be able to exercise in all noncontentious legal matters in firms of lawyers in the PRC. However, they may not apply Chinese law.

Hong Kong legal firms which have representative offices in the People's Republic are allowed to exercise jointly with Chinese firms, except in the form of commercial partnerships.

The most recent statistics, from mid-2003, found 51 subsidiaries of Hong Kong firms (59 offices) in the PRC. CEPA could lead to a noticeable increase in the number of Hong Kong lawyers in the PRC.

\section{Wholesale and retail trade, imports and exports}

The main advantages conceded to Hong Kong companies relate to the possibility of creating organisations which they control totally before this possibility is opened up to other foreign companies, and to the relaxing of access criteria, in particular the lowering of turnover thresholds. The advantage of these measures is called into question by the new legislation which liberalises access to this type of activity.

\section{"Added value" services in telecommunications}

Annex 4 of CEPA allows Hong Kong service providers to establish, from October 1st 2003 (while the measures for the other 17 sectors only came into effect on January 1st 2004), joint ventures in mainland China in order to provide one of the following five "added value services": Internet access, call centres, Internet data services, content provision, "store and forward" services (which secure the transmission of data when the network is weak or non-existent). Moreover these services can be offered without any geographical restrictions, which gives Hong Kong companies a little more than a year's head start over other foreign companies, to which these measures will apply in January 2005. However the stake of Hong Kong companies will be restricted to $49 \%$, as with other foreign companies.

\section{NOTES}

1. This article has benefited from the work and comments of Laurence Appert-Versini and Pascal Fürth, of the French Trade Commission in Hong Kong. 
2. For further information on the various sectors and the measures called for, the complete text of the CEPA and the annexes can be consulted on the Hong Kong Government site, http://www.tid.gov.hk/english/cepa/. The Hong Kong Trade Development Council (HKTDC) and the Hong Kong General Chamber of Commerce publish abundant documentation on the agreement and its ramifications. Part of this documentation is available online on their respective sites : www.tdctrade.com and www.hkgcc.org.hk. 